\title{
Diagnostic Endoscopy of Intestinal Strongyloidiasis in an Immunocompetent Patient by Single Balloon Enteroscopy
}

\author{
Dias $\mathrm{C}^{1 *}$, Landaeta J ${ }^{2}$ and Armas $\mathrm{V}^{3}$ \\ ${ }^{1}$ Clínica Santiago de León, USA \\ ${ }^{2}$ Policlínica Metropolitana, USA \\ ${ }^{3}$ GastroExpress, USA
}

Submission: December 28, 2017; Published: January 10, 2018

*Corresponding author: Dias C, Clínica Santiago de León, Caracas-Venezuela, USA, Email: endoscopistadracarla@gmail.com

\begin{abstract}
Strongyloides stercoralis is an intestinal nematode that is able to infect the host tissue and persist for many years through autoinfection, and it causes life-threatening hyperinfection in immunocompromised hosts. Diagnosis of strongyloidiasis is usually made by identifying the larvae in the stool or in duodenal biopsies. There are only two published cases reports of strongyloidiasis diagnosed by double balloon enteroscopy .We report one case of strongyloidiasis that was diagnosed by single balloon enteroscopy (SBE) biopsy. A 40 -year-old man who was hospitalized with complaints of watery diarrheas and weight loss. SBE showed the mucosa of the duodenum and jejunum diffusely abnormal marked by edema, friability and multiple whitish lesions surrounded by reddish mucosa. Examination of biopsy specimens revealed a lympho-eosinophilic infiltration of the lamina propria with the presence of Strongyloides stercoralis in numerous gland crypts.

Keywords: Strongyloides stercoralis; Single balloon enteroscopy (SBE); Immunocompetent patient
\end{abstract}

\section{Introduction}

Strongyloidiasis is endemic in many countries throughout the tropical and temperate regions [1-4]. It is also associated with poor sanitation. Humans are infected by the third-stage filariform larvae of Strongyloides stercoralis. After they penetrate the skin, petechiae, maculopapular rashes and urticaria occur [5]. They then migrate via the respiratory tree, are swallowed with sputum and they eventually mature into the adult form in the duodenum and upper jejunum. The host-parasite relationship can be broken due to certain predisposing factors such as corticosteroid therapy, anticancer drug, malnutrition, severe burn and so on $[2,6,7]$. This gives rise to a pathologic state of hyperinfection, causing clinical manifestations in many organs [8]. Yet the diagnosis of strongyloidiasis can be difficult because the clinical symptoms, and especially the gastrointestinal manifestations, may vague or mimic several other conditions such as inflammatory bowel diseases, and the worm is observed in only $2 \%$ of patients on endoscopic mucosal biopsy [4].

Herein, we report one case of intestinal strongyloidiasis that was diagnosed by SBE biopsy.

\section{Case Report}

A 40-year-old, man, presented with a three-month history of more than 10 watery diarrheas per day and loss of 10 kilos of body weight. Laboratory data reported eosinophilia with a C-reactive protein (CRP) concentration of $40 \mathrm{mg} / \mathrm{dL}$. Hemoglobin was 10,5gr/dl. A fecal sample and stool culture did not report alterations. Antibodies to tissue transglutaminase, endomysial antibodies and deamidated gliadin peptide (DGP) (IgA and IgG) were negative, including HIV infection. Chest x-ray was normal. The patient was initially treated with intravenous fluids for dehydration and antibiotic therapy. EGD and colonoscopy had normal results. The symptoms had significantly deteriorated. Forty eight hours after admission, an anterograde single balloon enteroscopy with ESB Olympus SIF Q-180 at about $280 \mathrm{cms}$ from the ligament of Treitz was performed and $\mathrm{CO} 2$ insufflation pump (Olympus) was used.

SBE showed mucosal areas of denuded villi in the duodenum and jejunum and multiple whitish lesions surrounded by reddish mucosa. Because the larvae invade the lymph vessels, resulting in lymphangiectasia in edematous enteritis, the appearance of 
white villi reflected villous atrophy/destruction and mucosal edema. In the jejunum, alternate areas of stenoses and dilatations were evidenced (Figures 1-8).

Microscopically, increased inflammatory exudate and eosinophils. Jejunal mucosa showed numerous cross sections of adult worms, eggs and larvae that were developing in crypts.

The patient was treated with two cycles of albendazole $400 \mathrm{mg} / \mathrm{d}$ for 7 days. At 6-month follow up, he had no diarrhea and gained $5 \mathrm{~kg}$ of body weight. He continues to do well 12 months later resulted in complete recovery.

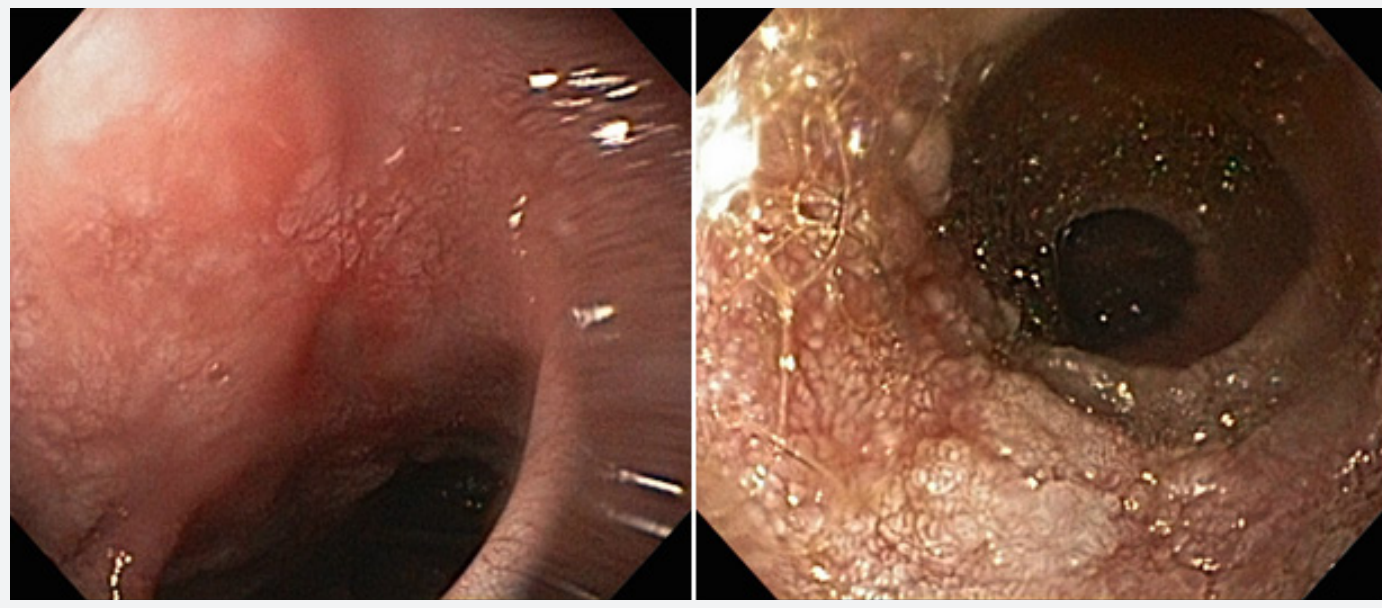

Figure 1 \& 2: Duodenum and Jejunum: diffusely abnormal mucosa.

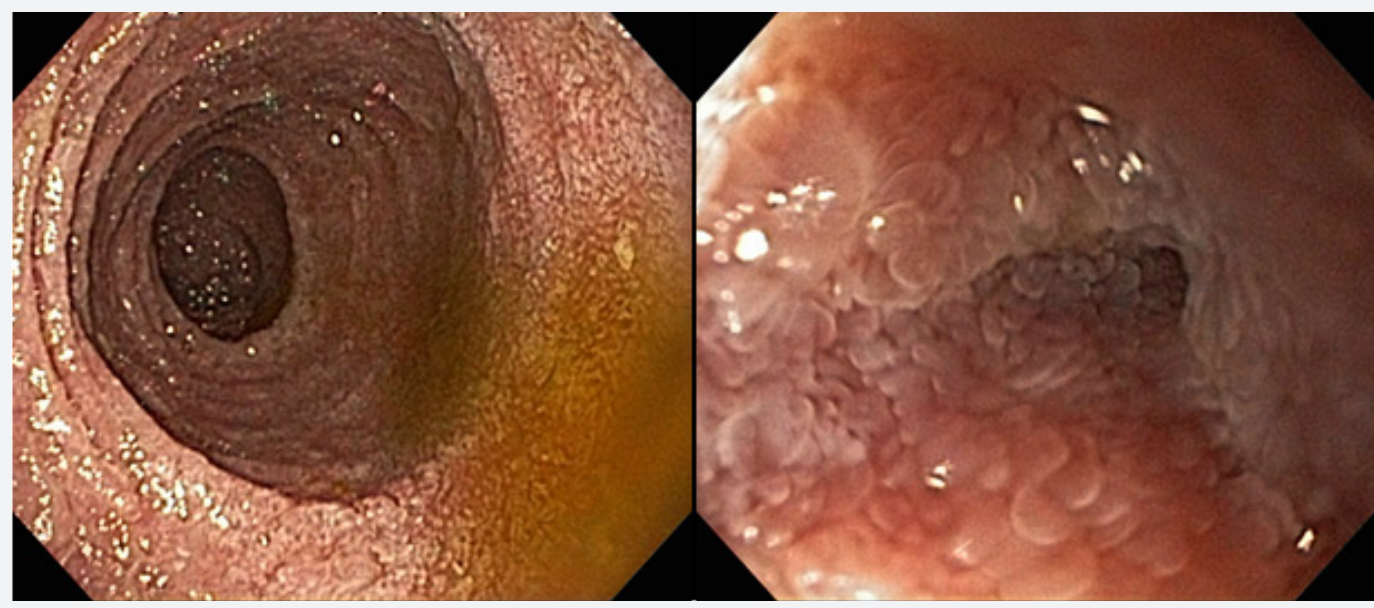

Figure 3 \& 4:Jejunum: Lymphangiectasia in edematous enteritis.

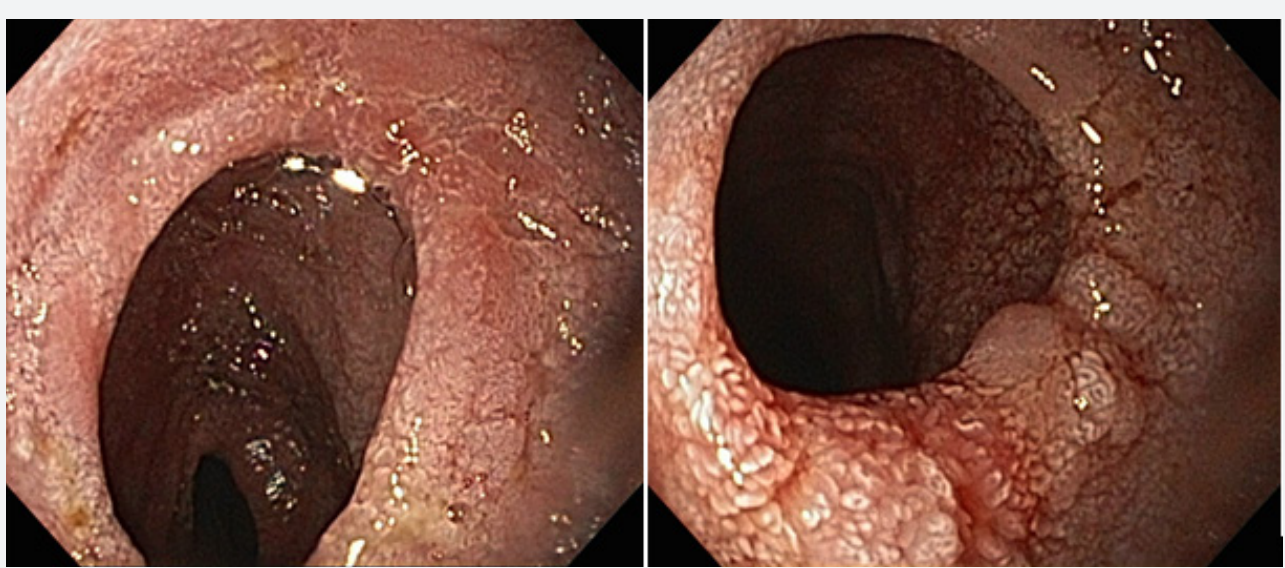

Figure 5 \& 6: Jejunum: Multiple whitish lesions surrounded by reddish mucosa. 


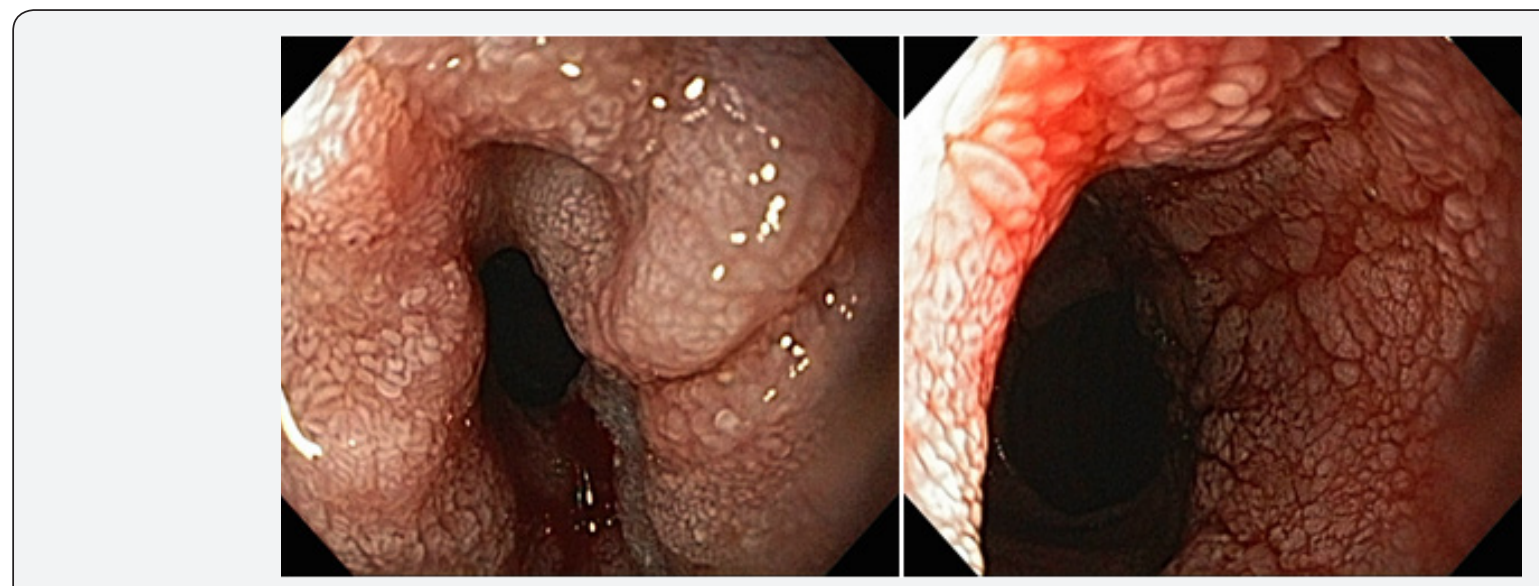

Figure 7 \& 8: Jejunum: alternate areas of stenoses and dilatations.

\section{Discussion}

Human infection with the intestinal nematode Strongyloides stercoralis is prevalent in tropical and subtropical regions of the world. S. stercoralis infection also is endemic in some parts of Europe, the southeastern United States, and Puerto Rico.

Biologically, S. stercoralis is unique among human helminths, which, as a rule, do not multiply within the definitive host. This worm is capable of reproducing within the human host. The normal autoinfection cycle involves the release of parasite larvae by adult worms in the gastrointestinal tract, and instead of passing to the outside environment in feces, they change into infective larvae and penetrate the gut wall or penanal skin of the same individual [9].

Primary infection with S. stercoralis is initiated through skin penetration by the infective filariform larvae. This acute infection with the early stage of the pathogen in the human host is usually asymptomatic. Larva currens is a more frequent cutaneous manifestation that occurs in association with autoinfection. It is an allergic reaction to filariform larvae that migrate in the skin at a relatively fast rate and leave itchy urticarial tortuous tracks [9].

By the time that the adult female worms reach maturity in the gastrointestinal tract, abdominal symptoms and signs may be observed [10]. In a controlled study, the following complaints were significantly more prevalent in infected individuals: indigestion, crampy abdominal pain, diarrhea with malabsorption, and weight loss [10]. These features are related to thickening and congestion of the mucosal lining of the small and large intestine in addition to frequent mucosal ulceration. Steatorrhea, malabsorption, protein-losing enteropathy, and paralytic ileus are the common physiological abnormalities seen in patients with gastrointestinal strongyloidiasis. Radiographic findings associated with gastrointestinal strongyloidiasis include duodenal edema with irregular mucosal folds, ulcerations, and strictures. Eosinophilia is a common finding, as is elevation of levels of nonspecific and specific IgE. The sensitivity of stool examination for parasites is poor. Examination of a single stool sample may miss $70 \%$ or more of cases owing to a low parasite burden and intermittent larvae excretion [11]. Specialized testing of stool samples with the Baerman concentration technique or a modified agar plate method can increase the yield. Also, aspiration of duodenojejunal fluid may be helpful. Alternatively, serologic testing may be useful [12]. This was not done in our patient because the diagnosis was established from the SBE and biopsy findings.

In the literature, there is a one report of Strongyloides stercoralis infection diagnosed by video capsule endoscopy in an immunocompetent patient [13] and two published case reports, where the diagnosis of the infection was only made by biopsies obtained with double balloon enteroscopy $[14,15]$.

The most significant clinical presentation of strongyloidiasis occurs in patients with the hyperinfection syndrome [16]. Because of the massive tissue invasion with S. stercoralis larvae, symptoms and signs manifest as an exaggeration of the clinical features of established infection in immunocompetent patients. Furthermore, invasion of multiple organs leads to manifestations related to these organs. Finally, the introduction of bowel organisms results in bacteremia and septicemia.

The first-line therapy for strongyloidiasis is ivermectin, which achieves eradication rates of approximately 80\%. Other effective agents include thiabendazole $25 \mathrm{mg} / \mathrm{kg}$ of body weight is administered orally for 2 or 3 days and 7-10 days for patients with the hyperinfection syndrome, or albendazole $400 \mathrm{mg} / \mathrm{d}$ for 7 days. Often, a single course of treatment is insufficient and whether a second course of therapy should be given. Resolution of eosinophilia does not always indicate clearance of Strongyloides. Because it is difficult to clinically confirm eradication of the infection, many experts prefer to repeat a 2-day course of therapy 1 week after the initial course, with careful follow-up in patients with persistent symptoms and/or infection [17].

\section{Conclusion}

The present case is illustrative of the challenges in diagnosing Strongyloidiasis in immunocompetent patients. S. stercoralis hyperinfection can rapidly become fatal, so early diagnosis and 
treatment is very important. The SBE may play an important role in the diagnosis of intestinal strongyloidiasis. This should be included within the diagnostic algorithm. The early diagnosis of intestinal strongyloidiasis allows the introduction of therapy with complete recovery.

\section{References}

1. Choi KS, Whang YN, Kim YJ, Yoon MY, Kyung Y, et al. (1985) A case of hyperinfection syndrome with Strongyloides stercoralis. Korean J Parasitol 23(2): 236-240.

2. Goh SK, Chow PK, Chung AY, Tan BH, Tan PH, et al. (2004) Strongyloides colitis in a patient with Cushing's syndrome. Gastrointest Endosc 59(6): 738-741.

3. Kim DS, Kong HH, Lee CH, Lee CK, Jung DI, et al. (2004) Synopsis of clinical parasitology. (1 $1^{\text {st }}$ edn). Seoul: Panmun 124-131.

4. Sang CN, Man HH, Young SK, Yoon SK, In SS, et al. (2007) Two cases of strongyloidiasis diagnosed by colonoscopic biopsy. The Korean Journal of Pathology 41(5): 343-346.

5. Kim NR, Kim DS, Han J, Choe DC (2002) Fatal strongyloidiasis with residual cutaneous larvae: an autopsy case report. Korean J Pathol 36(4): 266-270

6. Lee MK, Kim YK, Hwang IS (1997) A case of Strongyloides stercoralis infection associated with long-term adminstration of steroid in a patient with alcoholic liver disease. Korean J Gastrointest Endosc 17: 675-679.

7. Kim J, Joo HS, Kim DH, Lim H, Kang YH, et al. (2003) A case of gastric strongyloidiasis in a Korean patient. Korean J Parasitol 41(1): 63-67.
8. Hong SJ, Shin JS, Kim SY (1988) A case of strongyloidiasis with hyperinfection syndrome. Korean J Parasitol 26: 221-226.

9. Mahmoud A (1996) Strongyloidiasis. Clinical Infectious Diseases 23: 949-953.

10. Grove DI (1994) Strongyloidiasis: a conundrum for gastroenterologists. Gut 35(4): 437-440.

11. Sang CN, Man HH, Young SK, Yoon SK, In SS, et al. (2007) Two cases of strongyloidiasis diagnosed by colonoscopic biopsy. J Pathol Transl Med 41(5): 343-346.

12. Sridhara S, Simon N, Raghuraman U, Crowson N, Aggarwal V, et al. (2008) Strongyloides stercoralis pancolitis in an immunocompetent patient. Gastrointest Endosc 68(1): 196-199.

13. Xouris D, Vafiadis ZI, Papaxoinis K, Giorgos B, George K, et al. (2012) Possible Strongyloides stercoralis infection diagnosed by video capsule endoscopy in an immunocompetent patient with devastating diarrhea. Ann Gastroenterol 25(3): 268-270.

14. Hsu WH, Yang SF, Su YC (2009) Strongyloides stercoralis ileitis detected by double-balloon endoscopy. Endoscopy 41(Suppl 2): E292-E293.

15. Nakamura N, Matsushita M, Tahashi Y, Shimatani M, Aoi K, et al. (2010) Diagnostic yield of double-balloon enteroscopy with intestinal juice analysis for intestinal strongyloidiasis. Dig Endosc 22(4): 370-372.

16. Liu LX, Weller PF (1993) Strongyloidiasis and other intestinal nematode infections. Infect Dis Clin North Am 7(3): 655-682.

17. Kassalik M, Mönkemüller K (2011) Strongyloides stercoralis hyperinfection syndrome and disseminated disease. Gastroenterol Hepatol (N Y) 7(11): 766-768.

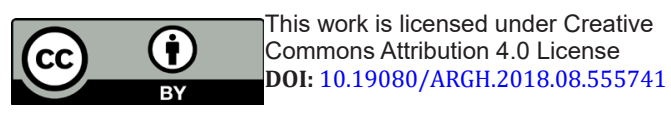

Your next submission with JuniperPublishers
will reach you the below assets
- Quality Editorial service
- Swift Peer Review
- Reprints availability
- E-prints Service
- Manuscript Podcast for convenient understanding
- Global attainment for your research
- Manuscript accessibility in different formats
( Pdf, E-pub, Full Text, audio)
- Unceasing customer service
Track the below URL for one-step submission
https://juniperpublishers.com/online-submission.php

